\title{
Sundarban as a Buffer against Storm Surge Flooding
}

\author{
Mohiuddin Sakib, Fatin Nihal, Anisul Haque, Munsur Rahman, Mansur Ali \\ Bangladesh University of Engineering and Technology, Dhaka, Bangladesh \\ Email: sakib.mohiuddin06@gmail.com, sarkar.fatin@gmail.com
}

Received 28 July 2015; accepted 15 October 2015; published 22 October 2015

\begin{abstract}
Sundarban, the largest mangrove forest in the world, is known to act as a buffer against the cyclone and storm surge. Theoretically, Sundarban absorbs the initial thrust of the wind and acts to "resist" the storm surge flooding. The role of Sundarban was evident during the cyclone Sidr when the Sundarban solely defended the initial thrust of the cyclonic wind and the resulting storm surge inundation. In doing this, Sundarban sacrificed $30 \%$ of its plant habitats. Although no scientific study has yet been conducted, it is generally believed that Sundarban will continuously play its role as a buffer against the cyclone when landfall of the cyclone is at or close to the Sundarban. Considering these facts, the present study mainly focused on a scientific insight into the role of Sundarban as a buffer against the present-day cyclone and storm surge and also its probable role on the impacts of future storms of similar nature but with different landfall locations. The Delft 3D dashboard and flow model are applied to compute the resulting inundation due to cyclone induced storm surge. The results show that Sundarban indeed acts as a buffer against the storm surge inundation when cyclone landfall is at or close to Sundarban.
\end{abstract}

\section{Keywords}

Buffer, Mangrove Forest, Sidr, Landfall, Roughness

\section{Introduction}

Mangroves are the unique ecosystem that provides a wide range of ecosystem services [5]. Mangrove also plays a significant role in reducing the intensity of cyclones and the resulting inundation [6]. The world's largest single tract mangrove forest located in Bangladesh and India - the Sundarban also provides a wide range of ecosystem services and largely contributes to socio-economic development of the communities directly or indirectly influenced by Sundarban [5]. A number of studies have been conducted regarding the importance of Sundarban as ecosystem service provider [5].

The studies mentioned above mainly focused on services provided by Sundarban—but not specifically the role of Sundarban as a buffer against the storm surge flooding. Storm surge flooding is a regular phenomenon in the region that causes immense loss and lives and properties. Since the known history, about 259 cyclones of different magnitude hit the Bangladesh coast [4]. Among these events, it was widely believed that Sundarban played a vital role in diminishing the effects of these cyclones [3]. The myth became a belief when in 2007, 
cyclone SIDR, which made landfall east of Sundarban was largely defended by Sundarban [5].

This study mainly focused for an in-depth analysis about the role of Sundarban as a buffer against the storm surge flooding. Several scenarios are constructed with SIDR and SIDR-like cyclones. Based on these-both the impact zone of Sundarban relevant to the storm surge flooding and possible role of Sundarban in reducing this flooding are studied. To achieve these objectives-Delft 3D Dashboard and Flow models [1] are used.

\section{Study Area}

The study area selected comprises the South-West region of Bangladesh including the Sundarban (Figure 1). The area taken is believed to be the maximum area that might be influenced by Sundarban if a cyclone makes landfall in the region. The Sundarban itself is divided into three regions (Figure 1). The lower part (35\% of the total Sundarban area) is considered as densely populated with the plant habitats and thus is most effective in reducing the thrust of a cyclone and the resulting inundation. These impacts slowly diminish when middle (35\% of the total area of Sundarban) and lower (30\% of the total area of Sundarban) parts are considered. The diminishing effects are assumed to be caused mainly by the human activities which are likely to be the maximum in the upper part. Figure 1 also shows actual track of cyclone SIDR (SIDR-ACTUAL) and a hypothetical track of SIDR-like cyclone (SIDR-LIKE) that made landfall just at the Sundarban. These two cyclone scenarios are considered in the present study.

\section{Model Description}

Delft 3D flow model coupled with cyclone generating Dashboard model are applied to simulate the land inundation due to storm surge. Time series of discharge is specified as the upstream boundary condition, with a time series of water level for the downstream boundary condition. Discharge data is used from the measurement of Bangladesh Water Development Board (BWDB) for the year (2007). For downstream water level boundaries, tides are generated by using GCOMS [8] data for the year (2007).

Cross sectional data for each of the estuarine systems of the GBM delta are measured under the ESPA delta project (http://www.espa.ac.uk). The domain of the measurements covers the entire study area. Open access General Bathymetric chart of the Oceans (GEBCO) data is used as the bathymetry of the Bay of Bengal. The inland ground elevation data is collected from Centre for Environmental and Geographic Information Services (CEGIS), Bangladesh.

As shown in Table 1, capacity of Sundarban as a buffer against the storm surge inundation is calculated based on relative roughness of different zones of Sundarban (see Figure 1). For scenario-1, the entire Sundarban is

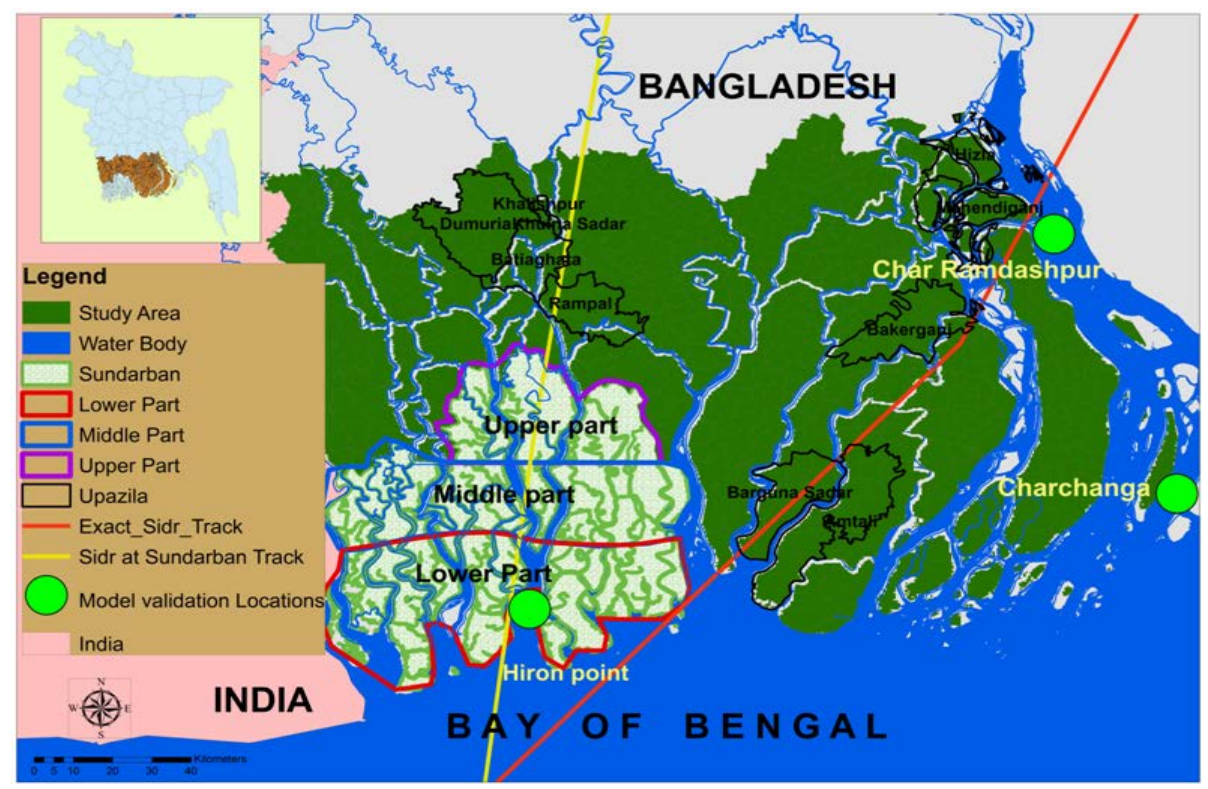

Figure 1. Study area with cyclone tracks. 
Table 1. Scenarios used to describe Sundarban as a buffer.

\begin{tabular}{cc}
\hline Scenarios & Capacity of Sundarban to act as a buffer against storm surge inundation \\
\hline Scenario-1 & $100 \%$ \\
Scenario-2 & $85 \%$ \\
Scenario-3 & $50 \%$ \\
Scenario-4 & $25 \%$ \\
Scenario-5 & $0 \%$ \\
\hline
\end{tabular}

effective to act as a buffer against the storm surge inundation. For scenario-5, Sundarban is not all effective as a buffer against the storm surge inundation. The rest of the scenarios lie in between these two extremes.

\section{Model Calibration and Validation}

The storm surge model is calibrated and validated with cyclone "SIDR". Calibration and validation locations are shown in Figure 1. Performances of the model during the calibration exercises are evaluated by computing the model reliability as described by Haque et al. (unpublished). Using this indicator, model reliability for the storm surge model for the "most acceptable model parameters" is obtained approximately 60\%. The calibrated model is then validated where measured tidal water level was available during the time of landfall of the cyclone. The calibration and validation performances of the model are shown in (Figure 2).

\section{Results}

\subsection{Influence Zone of Sundarban}

Influence zone means the area that is impacted by the presence of Sundarban due to storm surge flooding. Inundation area and depth are two main indicators for selecting influence zones for both cases. When the landfall location of Sidr is close to Sundarban (as of SIDR-ACTUAL case) then the influence zone of Sundarban is found outside the Sundarban itself. With the gradual reduction of the function of Sundarban as buffer against the storm surge flooding, it has been found that influence zone remains the same. Opposite results have been found when landfall location is exactly at Sundarban (SIDR-LIKE case). In this case, the influence zone is mainly concentrated within the vicinity of Sundarban itself. The influence zone of Sundarban due to SIDR-ACTUAL and SIDR-LIKE scenarios are shown in Figure 3 and Figure 4.

\subsection{Inundation Area}

For the SIDR-ACTUAL case, the maximum inundation area is found to be outside of Sundarban (Figure 5) when landfall is close to Sundarban. No significant change in inundation area is found due to role of Sundarban as a buffer. Figure 5 shows the total inundation area and its trend for outside and within Sundarban. From Figure 5 it is evident that when cyclone landfall is outside the Sundarban (SIDR-ACTUAL case), role of Sundarban in reducing the resultant inundated area due to cyclone induced storm surge inundation is not significant. Figure 6 shows a similar comparison, but this time for a cyclone that makes landfall exactly at Sundarban (SIDR-LIKE case, see Figure 1). Figure 6 shows that for SIDR-LIKE cyclones Sundarban indeed reduces the resultant inundated area within the Sundarban-influenced zone when Sundarban can effectively play its role as a buffer against the storm surge.

\subsection{Inundation Depth}

Upazila are the second lowest regional administrative unit in Bangladesh. Storm surge inundation depths for some particular upazila (see Figure 1) are calculated within the Sundarban-influenced zone for both SIDRACTUAL and SIDR-LIKE cases. For the SIDR-ACTUAL case, no significant change of inundation depth is found (Figure 7). But scenarios are reverse for SIDR-LIKE cyclones that makes landfall exactly at Sundarban (see Figure 8). In this case inundation depth increases as Sundarban slowly loses its capacity to act against the cyclone and the resulting storm surge. 


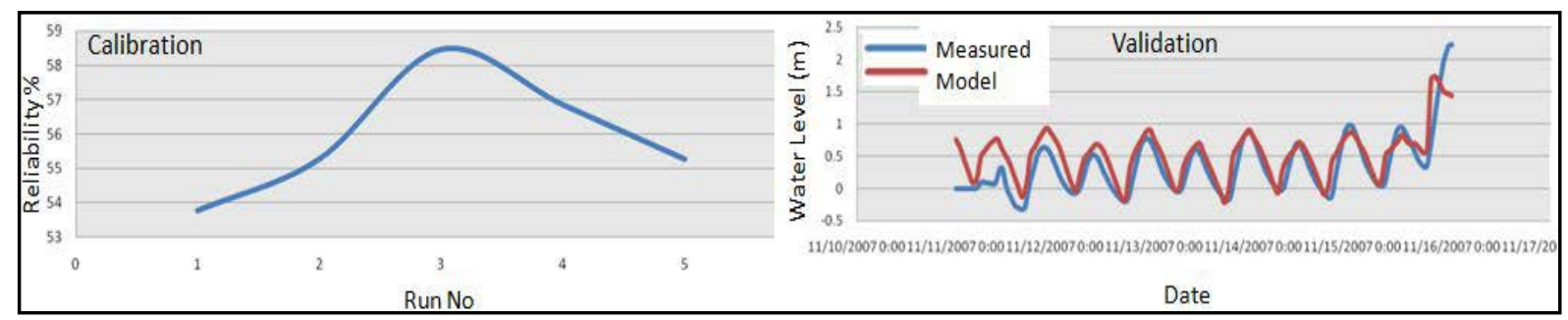

Figure 2. Model calibration and validation.

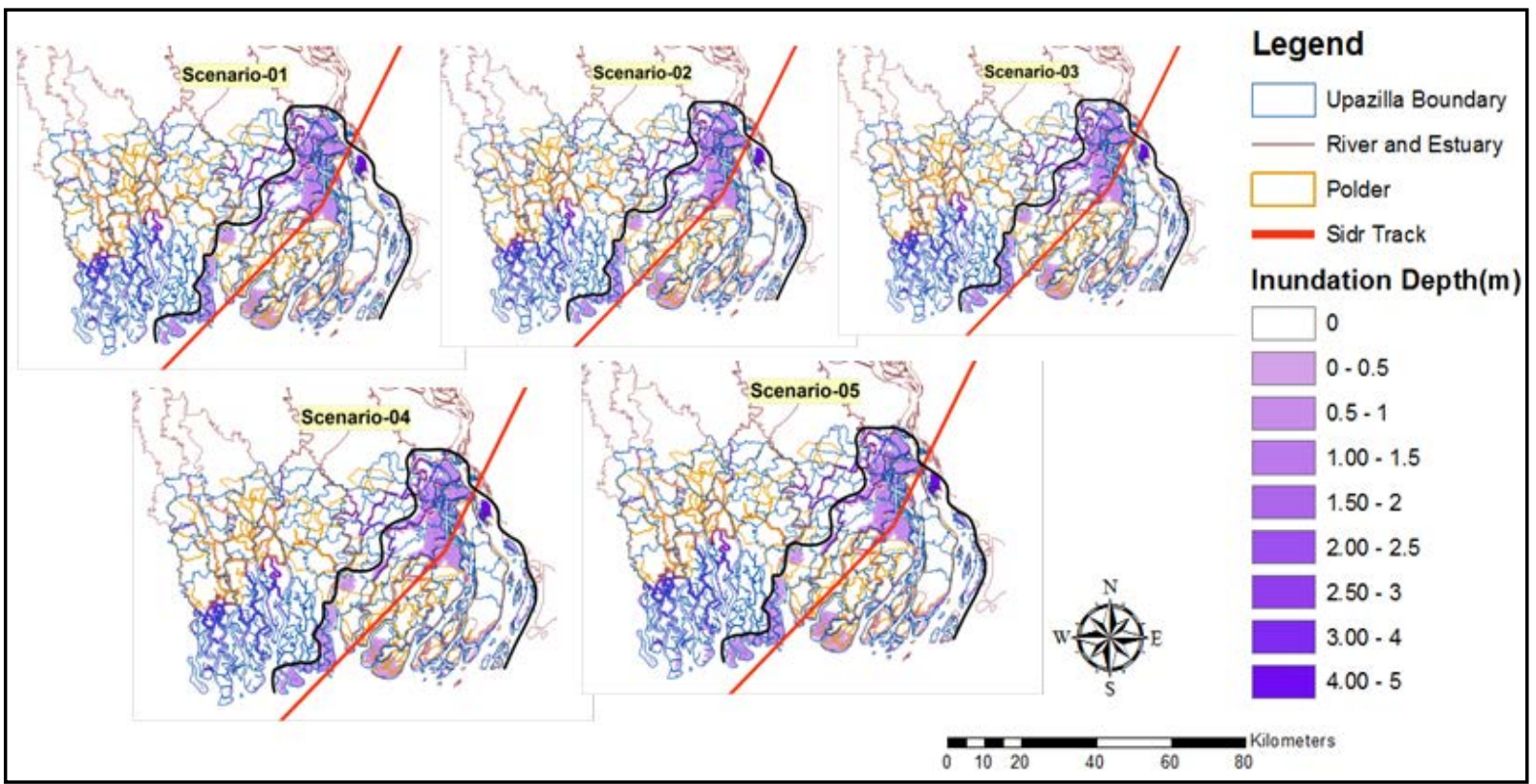

Figure 3. Influence zone for SIDR-ACTUAL cyclone.

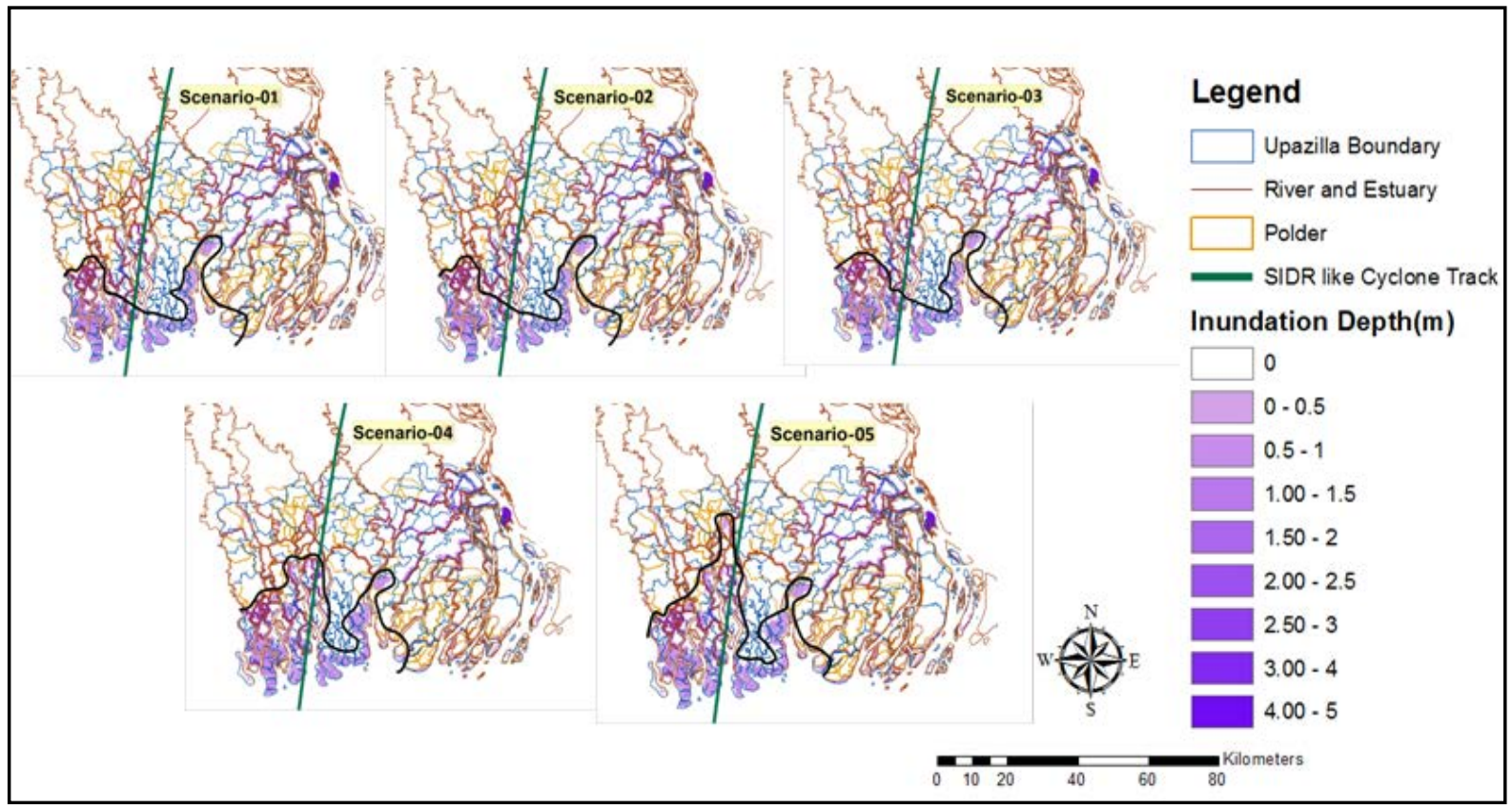

Figure 4. Influence zone for SIDR-LIKE cyclone. 


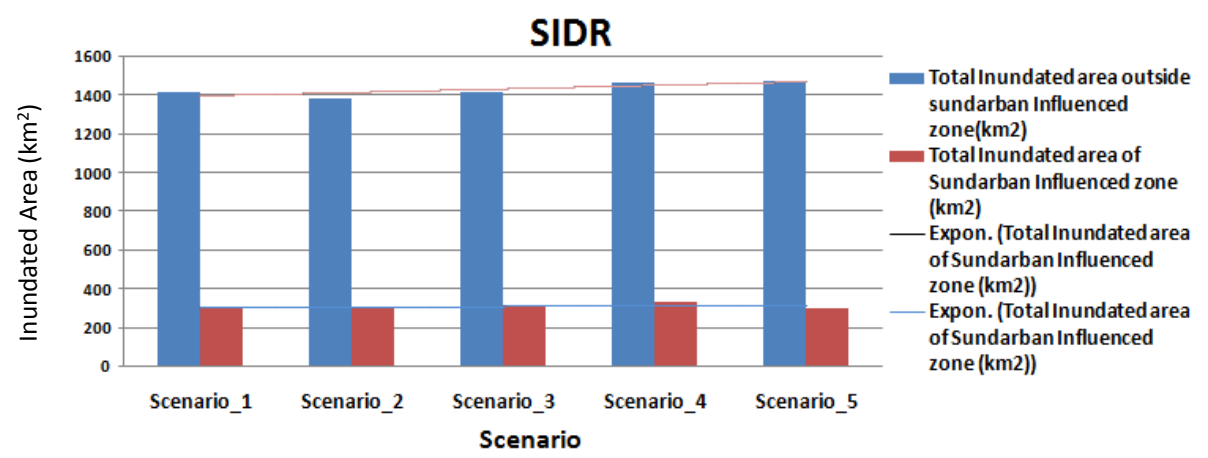

Figure 5. Inundation area for Sidr-actual cyclone.

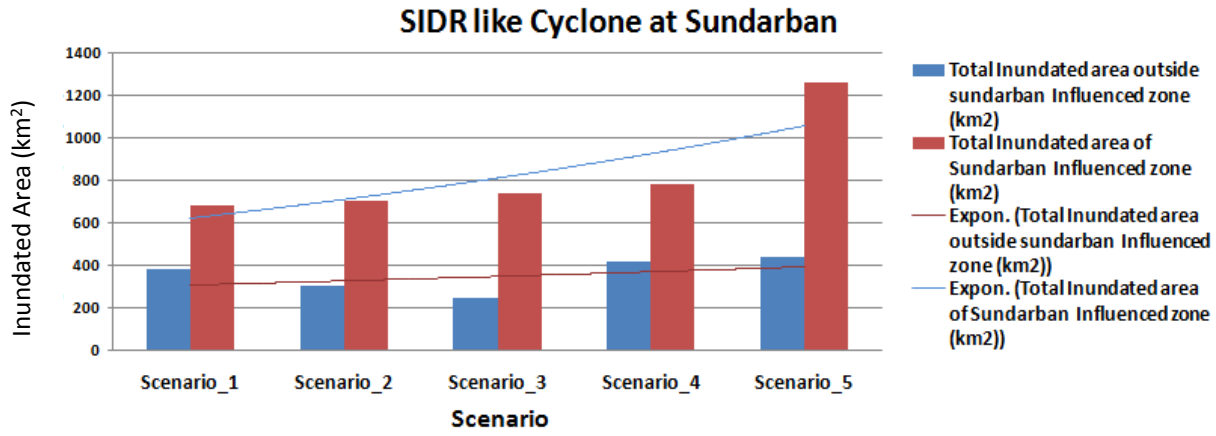

Figure 6. Inundation area for Sidr-like cyclone.

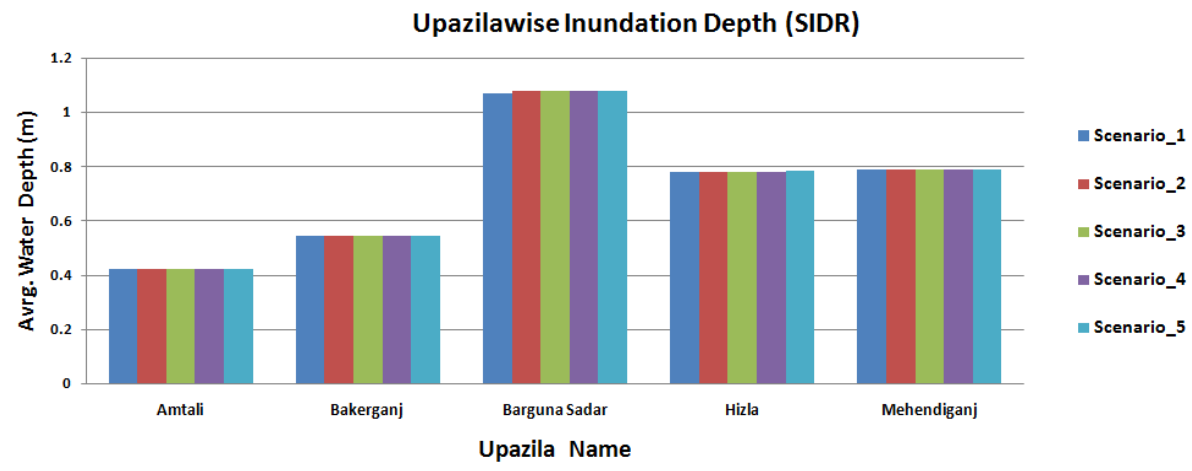

Figure 7. Inundation depths due to SIDR-actual cyclone.

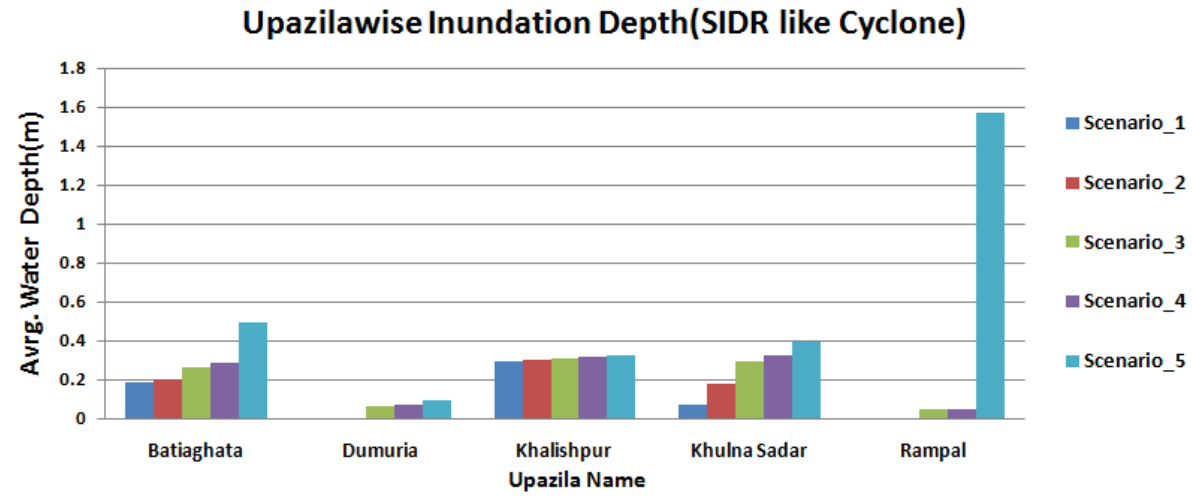

Figure 8. Inundation depths due to SIDR-like cyclone. 


\section{Conclusion}

Sundarban as a buffer against storm surge has significant impact in reducing the inundated area and depth when landfall location of a cyclone is exactly at Sundarban But it is insignificant when landfall location is outside of Sundarban. The impact of Sundarban is mainly confined within the Sundarban-influenced zone of a cyclone.

\section{Acknowledgements}

The authors would like to acknowledge to ESPA for funding this work as part of the ESPA Deltas project (Grant Reference Code: NEJ0027551). We would like to acknowledge the contribution of other members associated with the research team who has direct and indirect input to this work.

\section{References}

[1] Rahman, M.M., Haque, A., Nicholls, R.J., Jisan, M.A., Nihal, F., Ahmed, I. and Lázár, A.N. (2015) Storm Surge Flooding in the Ganges-Brahmaputra-Meghna Delta: Present and Future Scenarios. E-proceedings of the 36th IAHR World Congress 28 June-3 July 2015, The Hague, The Netherlands.

[2] Haque, A., Sumaiya, S., Salehin, M. and Rahman, M. (unpublished) Reliability Analysis of Dynamic Models.

[3] Roy, T.K. and Hossain, S.T. (2015) Role of Sundarbans in Protecting Climate Vulnerable Coastal People of Bangladesh. Climate Change, 1, 40-44.

[4] World Bank, Ecomics of Adaptation to Climate Change Bangladesh, World Bank, Ministry of Forieng Affairs Government of Netherlands, DFID United Kingdom, Swiss Agency for Development and Cooperation SDC. (C) 2010 The World Bank Group.

[5] Uddin, M.S., Shah, M.A.R., Khanom, S. and Nesha, M.K. (2013) Climate Change Impacts on the Sundarbans Mangrove Ecosystem Services and Dependent Livelihoods in Bangladesh. Asian Journal of Conservation Biology, 2, 152156.

[6] McIvor, A., Spencer, T., Möller, I. and Spalding, M. (2012) Storm Surge Reduction by Mangroves, NCP Report 2012-02.

[7] Haque, A., Sumaiya and Rahman, M. (2016) Flow Distribution and Sediment Transport Mechanism in the Estuarine Systems of Ganges-Brahmaputra-Meghna Delta. International Journal of Environmental Science and Development, 7, No. 1.

[8] Matsumoto, K., Takanezawa, T. and Ooe, M. (2000) Ocean Tide Models Developed by Assimilating TOPEX/ POSEIDON Altimeter Data into Hydrodynamic Model: A Global Model and a Regional Model Around Japan. Journal of Oceanography, 56, 567-581. http://dx.doi.org/10.1023/A:1011157212596 